\title{
Commentary \\ Circulating pro-apoptotic mediators in burn septic acute renal failure
}

\author{
Heleen M Oudemans-van Straaten
}

Department of Intensive Care, Onze Lieve Vrouwe Gasthuis, Oosterpark, 1091 AC Amsterdam, Netherlands

Corresponding author: HM Oudemans-van Straaten, h.m.oudemans-vanstraaten@olvg.nl

Published: 31 March 2008

This article is online at http://ccforum.com/content/12/2/126

(c) 2008 BioMed Central Ltd

See related research by Mariano et al., http://ccforum.com/content/12/2/R42
Critical Care 2008, 12:126 (doi:10.1186/cc6798)

\begin{abstract}
The pathogenesis of septic acute kidney injury (AKI) is not well understood. In the present issue of Critical Care, the combined clinical and experimental study from Mariano's group provides new insight into the disease. The study shows that plasma from septic burn patients with acute renal failure initiated pro-apoptotic effects and functional alterations in renal tubular cells and podocytes in vitro that correlated with the degree of proteinuria and renal dysfunction. Pro-apoptotic effects were not attributable to antibiotic or uremic toxicity, but were partially attributable to endotoxin. Sepsis and burn had additive effects. Apart from increasing our understanding of the pathogenesis of septic AKI, the study justifies further research on therapeutic interventions in several directions. These include the binding and elimination of the source of endotoxin by selective decontamination of the digestive tract, the blocking of apoptotic pathways, or the extracorporeal removal of circulating toxic mediators using high permeability hemofiltration or coupled plasma filtration and absorption.
\end{abstract}

We still have no uniform concept of the pathogenesis of septic acute kidney injury (AKI). While renal hypoperfusion is the predominant factor in hypodynamic states, neither systemic nor intrarenal vasomotor changes seem to be the sole contributor to $\mathrm{AKI}$ in sepsis. Inflammatory and procoagulatory mediators likely play an additional role. Yet, how they exactly injure the kidney is not well understood. Septic AKI occurs without obvious inflammatory infiltrates, vascular thrombosis and tubular cell necrosis.

\section{Circulating pro-apoptotic factors}

The elegant study of Mariano and coworkers [1] in this issue of Critical Care shows that acute renal failure in septic burn patients is characterized by proteinuria, attributable to both glomerular and tubular damage. The severity of proteinuria correlated with systemic inflammatory and procoagulatory markers, and with impairment of renal function and nonsurvival. In a series of in vitro experiments they demonstrated that circulating factors reduced the viability and function of tubular cells and podocytes, and caused upregulation of several pro-inflammatory and pro-apoptotic genes and proteins, and down-regulation of apoptosis inhibitors. Proapoptotic effects were not attributable to antibiotic or uremic toxicity, but were partially attributable to endotoxin. Sepsis and burns had additive effects on tubular apoptosis. A possible mediator of these circulating pro-apoptotic effects may have been tumor necrosis factor (TNF), which was detected in burn septic acute renal failure plasma.

\section{Apoptosis}

Cells either die from necrosis or from apoptosis. While necrosis results from energy depletion, apoptosis consumes energy and is triggered by the upregulation of genes. These genes encode proteins involved in several biochemical pathways that cause cell shrinkage, condensation of chromatin, damage to cell membranes and nuclear fragmentation. Apoptosis is crucial for tissue homeostasis, tumor surveillance and immune function. Nature allows inhibition of apoptosis at several stages in the complex biochemical cascade. Inhibition either initiates repair, leading to cell recovery, or brings the damage to a halt, allowing survival and replication of the injured cell with risk of creating a diseased clone. An example of repair is the activation of the protein kinase Akt by growth factors. Apoptosis is triggered by several mechanisms, including activation of the extrinsic pathway by ligation of the exposed part of the membrane receptors for Fas or TNF at the cell surface $[2,3]$.

\section{Directions of further research on therapeutic interventions}

Apart from increasing our understanding of the pathogenesis of septic AKI [4], the study of Mariano and colleagues justifies further research on therapeutic interventions in several directions. 


\section{Decreasing circulating endotoxin}

First, since the pro-apoptotic effects were partially attributable to endotoxin, strategies that decrease circulating endotoxin are likely to be beneficial. Patients with severe burns exhibit increased permeability of the gut and a blunted immunological defense, allowing endotoxin from the gut to enter the systemic circulation and Gram-negative organisms to cause infection [5]. Binding of gut derived endotoxin and elimination of potential pathogenic organisms with the use of enterally administered polymyxin and tobramycin can reduce circulating concentrations of endotoxin and TNF, and prevent gut-derived infections $[6,7]$

\section{Inhibition of apoptosis}

Second, inhibition of apoptosis may prevent initiation of the death pathway. Caspases are proteolytic enzymes effectuating the apoptotic death program. Caspase inhibitors have been used as anti-apoptotic agents, decreasing myocardial dysfunction and nuclear apoptosis after experimental endotoxemia [8]. However, although Fas signaling predominantly induces cell death via caspases, it also confers proliferative effects in fibroblasts and T cells. Consequently, caspase inhibition not only inhibits apoptosis, but also Fas-mediated stimulation of $T$ cell growth and can thus have unexpected harmful effects [9]. Before clinical implementation, blocking of distinct pro-apoptotic pathways needs further research and understanding.

\section{Extracorporeal blood purification}

Third, circulating mediators of apoptosis are principally accessible for extracorporeal blood purification. High volume hemofiltration, high permeability hemofiltration and coupled filtration and adsorption (CPFA) have been applied for this purpose. Removal of mediators with hemofiltration is determined by solute characteristics (size, charge, geometry and free fraction), membrane characteristics (pore size, surface area and absorptive features) and ultrafiltrate flow. Removal with hemofiltration is non-specific and never complete. This seeming limitation may actually be advantageous in critically ill patients with uncontrolled systemic inflammation. Nonspecific removal of peak concentrations of soluble mediators without complete elimination may allow restoration of a more favourable equilibrium [10].

Indeed, a higher dose of renal replacement therapy can improve patient survival $[11,12]$. However, although hemofiltration with conventional membranes can remove smaller inflammatory and pro-apoptotic mediators such as complement, platelet activating factor and interleukin-8, the use of high pore-size membranes is necessary for the substantial removal of TNF and caspases and restoration of apoptosismediated white blood cell dysfunctions [13-15]. Proapoptotic mediator removal can be increased further when filtered plasma is subsequently dialyzed and driven through an absorber. CPFA improved unselective cytokine removal, hemodynamics and leukocyte responsiveness in a preliminary human study [16]. Large randomized controlled trials are necessary to determine whether high permeability hemofiltration or the complex intervention of CPFA can mitigate apoptotic $\mathrm{AKI}$ and improve patient outcome.

\section{Conclusion}

The pathogenesis of septic AKI is not well understood. Mariano and coworkers found that plasma from septic burn patients with acute renal failure initiates pro-apoptotic effects and functional alterations in renal tubular cells and podocytes in vitro that correlate with the degree of proteinuria and renal dysfunction. Sepsis and burns had additive effects. This robust study provides new insight into the pathogenesis of septic AKI. The study of Mariano and colleagues additionally opens directions for research on therapeutic interventions mitigating septic AKI, including the binding and elimination of endotoxin in the gut, the blocking of apoptotic pathways and the extracorporeal removal of circulating pro-apoptotic mediators.

\section{Competing interests}

The author declares that they have no competing interests.

\section{References}

1. Mariano F, Cantaluppi V, Stella M, Romanazzi GM, Assenzio B, Cairo M, Biancone L, Triolo G, Ranieri VM: Circulating plasma factors induce tubular and gomerular alterations in burn septic patients. Crit Care 2008, 12:R42.

2. Chen G, Goeddel DV: TNF-R1 signaling: a beautiful pathway. Science 2002, 296:1634-1635.

3. Wajant $\mathrm{H}$ : The Fas signaling pathway: more than a paradigm. Science 2002, 296:1635-1636.

4. Wan L, Bellomo R, Di Giantomasso D, Ronco C: The pathogenesis of septic acute renal failure. Curr Opin Crit Care 2003, 9: 496-502.

5. Peng YZ, Yuan ZQ, Xiao GX: Effects of early enteral feeding on the prevention of enterogenic infection in severely burned patients. Burns 2001, 27:145-149.

6. de La Cal MA, Cerda E, Garcia-Hierro P, van Saene HK, GomezSantos D, Negro E, Lorente JA: Survival benefit in critically ill burned patients receiving selective decontamination of the digestive tract: a randomized, placebo-controlled, doubleblind trial. Ann Surg 2005, 241:424-430.

7. Martinez-Pellus AE, Merino P, Bru M, Conejero R, Seller G, Munoz C, Fuentes T, Gonzalez G, Alvarez B: Can selective digestive decontamination avoid the endotoxemia and cytokine activation promoted by cardiopulmonary bypass? Crit Care Med 1993, 21:1684-1691.

8. Neviere R, Fauvel $\mathrm{H}$, Chopin $\mathrm{C}$, Formstecher $\mathrm{P}$, Marchetti $\mathrm{P}$ : Caspase inhibition prevents cardiac dysfunction and heart apoptosis in a rat model of sepsis. Am J Respir Crit Care Med 2001, 163:218-225.

9. Cauwels A, Janssen B, Waeytens A, Cuvelier C, Brouckaert P: Caspase inhibition causes hyperacute tumor necrosis factorinduced shock via oxidative stress and phospholipase A2. Nat Immunol 2003, 4:387-393.

10. Ronco C, Tetta C, Mariano F, Wratten ML, Bonello M, Bordoni V, Cardona X, Inguaggiato P, Pilotto L, d'Intini V, Bellomo R.: Interpreting the mechanisms of continuous renal replacement therapy in sepsis: the peak concentration hypothesis. Artif Organs 2003, 27:792-801.

11. Ronco C, Bellomo R, Homel P, Brendolan A, Dan M, Piccinni P, La Greca G: Effects of different doses in continuous venovenous haemofiltration on outcomes of acute renal failure: a prospective randomised trial. Lancet 2000, 356:26-30.

12. Saudan $P$, Niederberger $M$, De Seigneux S, Romand J, Pugin J, Perneger T, Martin PY: Adding a dialysis dose to continuous hemofiltration increases survival in patients with acute renal failure. Kidney Int 2006, 70:1312-1317. 
13. Morgera S, Rocktäschel J, Haase M, Lehmann C, von Heymann C, Ziemer S, Priem F, Hocher B, Göhl H, Kox WJ, Buder HW, Neumayer $\mathrm{HH}$ : Intermittent high permeability hemofiltration in septic patients with acute renal failure. Intensive Care Med 2003, 29:1989-1995.

14. Bordoni V, Bolgan I, Brendolan A, Crepaldi C, Gastaldon F, d'Intini V, Pilotto L, Inguaggiato P, Bonello M, Galloni E, Everard P, Bellomo R, Ronco C: Caspase- $\mathbf{3}$ and $\mathbf{- 8}$ activation and cytokine removal with a novel cellulose triacetate super-permeable membrane in an in vitro sepsis model. Int J Artif Organs 2003, 26:897-905

15. Morgera $S$, Haase $M$, Rocktäschel J, Böhler T, Vargas-Hein $O$, Melzer C, Krausch D, Kox WJ, Baumann G, Beck W, Göhl H, Neumayer $\mathrm{HH}$ : Intermittent high-permeability hemofiltration modulates inflammatory response in septic patients with multiorgan failure. Nephron Clin Pract 2003, 94:c75-c80.

16. Ronco C, Brendolan A, Lonnemann G, Bellomo R, Piccinni P, Digito A, Dan M, Irone M, La Greca G, Inguaggiato P, Maggiore U, De Nitti C, Wratten ML, Ricci Z, Tetta C: A pilot study of coupled plasma filtration with adsorption in septic shock. Crit Care Med 2002, 30:1250-1255. 